\title{
KHẢO SÁT CÁC ĐIỀU KIỆN SINH TỔNG HợP CELLULASE TỪ Bacillus amyloliquefaciens D19
}

\author{
NGUYỄN NGỌC ẨN ${ }^{1}$, NGUYỄN LÊ HIỀ HÒA ${ }^{1}$, TRẦN NGUYỄN DIỄM LINH ${ }^{1}$, BÙI TH! \\ LUYẾN $^{2}$, NGUYẼ̃N THANH HẢI ${ }^{2}$, NGUYẼ̃N THỊ DIỆU HẠNH ${ }^{1}$, PHẠM TÂN VIẸT $^{1}$ \\ ${ }^{l}$ Viện Công nghệ Sinh học và Thưc phẩm, Truờng Đại học Công Nghiệp Thành phố Hồ Chí Minh \\ ${ }^{2}$ Truờng Đại học Khoa học Tự nhiên, Đại học Quốc gia Tp. Hồ Chí Minh, \\ phamtanviet@iuh.edu.vn
}

Tóm tắt. Cellulase là enzyme được thu nhận chủ yếu từ vi sinh vật, có tác dụng thủy phân cellulose thành các phân tử đường có cấu trúc đơn giản hơn và được ứng dụng nhiều trong xử lý môi trường cùng nhiều lĩnh vực công nghiệp khác nhau như công nghiệp giấy, may mặc, thực phẩm,... Trong nghiên cứu này, chúng tôi tiến hành khảo sát các điều kiện thích hợp cho sự sinh tổng hợp cellulase của chủng Bacillus amyloliquefaciens D19. Kết quả cho thấy sau khi nuôi cấy chủng vi khuẩn này trong môi trường có $\mathrm{pH}$ ban đầu là 5,0 bao gồm các thành phần như $0,5 \% \mathrm{rơm}, 1 \%$ bột đậu nành $(\mathrm{w} / \mathrm{v}), 1 \% \mathrm{NaCl}(\mathrm{w} / \mathrm{v}), 0,5 \%$ cao nấm men (w/v) sau 48 giờ ở điều kiện lắc 150 vòng/phút và nhiệt độ $37^{\circ} \mathrm{C}$, thì hoạt tính enzyme đạt cao nhất là $879,47 \mathrm{UI} / \mathrm{ml}$. Kết quả này sẽ làm tiền đề cho những nghiên cứu tiếp theo như khảo sát các điều kiện bảo quản chế phẩm cellulase thô thu nhận được từ chủng vi khuẩn này, nghiên cứu lên men ở qui mô pilot, qui mô công nghiệp để thu cellulase với số lượng lớn, nghiên cứu sâu nhằm sản xuất chế phẩm enzyme thương mại hoặc ứng dụng của cellulase cho nhiều mục đích khác nhau trên thực tiễn.

Từ khóa. Bacillus amyloliquefaciens, cellulase, enzyme ngoại bào, phân hủy cellulose.

\section{ENHANCED PRODUCTION OF CELLULASE FROM Bacillus amyloliquefaciens D19}

\begin{abstract}
Cellulase is an enzyme mainly produced by microorganisms, which hydrolyzes cellulose into monosaccharide and is widely used in environmental treatment and many different industrial sectors such as industrial paper, garment, food, ... In this study, we have found suitable culture conditions including substrate source, nitrogen source, carbon source, initial $\mathrm{pH}$, and culture temperature for Bacillus amyloliquefaciens D19 cellulase biosynthesis cellulase biosynthesis. The results showed that after culturing this strain in medium supplemented with $0,5 \%$ straw, $1 \%$ soy flour $(\mathrm{w} / \mathrm{v}), 1 \% \mathrm{NaCl}(\mathrm{w} / \mathrm{v}), 0,5 \%$ yeast extract (w/v) in 48 hours at shaking conditions $150 \mathrm{rpm}, 37^{\circ} \mathrm{C}$, initial $\mathrm{pH} 5,0$, the highest enzyme activity obtained was $879,47 \mathrm{UI} / \mathrm{ml}$. This result will pave the way for further studies such as investigating the storage conditions of raw cellulase products obtained from this strain of bacteria, conducting fermentation studies on pilot and industrial scale to obtain cellulase in large quantities and quality, production of commercial enzyme products or applications of cellulase for a variety of practical purposes.
\end{abstract}

Key words. Bacillus amyloliquefaciens, cellulase, exoenzyme, cellulose degradation.

\section{GIỚI THIỆU}

Cellulose được tổng hợp chủ yếu ở thực vật, là thành phần tạo nên độ cứng cho vách tế bào. Bên cạnh đó, cellulose còn được tạo ra bởi vi khuẩn, hay còn gọi là Bacterial Cellulose $(\mathrm{BC})$ thông qua quá trình polymer hóa các phân tử glucose thành chuỗi $\beta$-1,4-glucan. Một lượng lớn cellulose được tích lũy hằng ngày trong đất do các sản phẩm từ thực vật, cành lá hoa quả rụng xuống, cây cối chết đi, một phần do con người thải ra dưới dạng rác thải nông nghiệp như rơm rạ, rác thải thực phẩm, rác thải công nghiệp và sinh hoạt như giấy vụn, mùn cưa,... Các chất thải này nếu không được sử dụng hoặc không được tái chế sẽ gây ô nhiễm môi trường [1]. Bên cạnh đó, việc phân hủy cellulose bằng các tác nhân lý hóa cần phải có sự tác động của nhiều loại hóa chất không thông dụng hoặc ở điều kiện nhiệt độ và áp suất cao, mất nhiều thời gian $[2,3]$. Cellulase là enzyme được sản xuất chủ yếu bởi vi sinh vật, có khả năng xúc tác một cách hiệu quả quá trình phân giải cellulose thành các monosaccharide "đường đơn" như $\beta$-glucose hoặc thành các oligosaccharide và các polysaccharide ngắn hơn và không tạo ra các phụ phẩm độc hại [4]. Sự phân hủy cellulose có tầm quan trợng đáng kể về kinh tế, bởi vì nó giúp chuyển hóa thành phần chính cellulose của thực vật thành sản phẩm dễ tiêu thụ và sử dụng [5]. Do đó, cellulase được xem là một trong những loại enyzme được sử dụng 
phổ biến và được ứng dụng rộng rãi trong thực tế như xử lý các phế phụ phẩm nông nghiệp, xử lý môi trường, sản xuất nhiên liệu sinh học, ứng dụng trong các ngành công nghiệp như công nghiệp thực phẩm, làm giấy, may mặc... nhẳm gia tăng hiệu suất xử lý và chất lượng sản phẩm.

Việt Nam là nước có nền nông nghiệp truyền thống và đang trong quá trình công nghiệp hóa, hiện đại hóa, chính vì vậy, để có được một nền kinh tế phát triển bền vững, vừa gia tăng số lượng và chất lượng sản phẩm trong một số ngành công nghiệp sản xuất, vừa giải quyết được vấn đề ô nhiễm môi trường gây ra bởi lượng rác thải hữu cơ (đa số có thành phần cellulose) thì việc nghiên cứu sản xuất ra lượng lớn cellulase là điều tất yếu. Trong đó, vi sinh vật là nguồn sản xuất cellulase tiềm năng bởi khả năng sinh sản, phát triển với tốc độ cực kỳ nhanh và sinh tổng hợp lượng lớn các enzyme ngoại bào có hoạt tính cao. Thêm vào đó, nghiên cứu sản xuất cellulase từ Bacillus amyloliquefaciens đã và đang là mối quan tâm của nhiều nhà khoa học trên thế giới [6-8]. Chính vì vậy, chúng tôi đã tiến hành khảo sát các điều kiện nuôi cấy thích hợp cho sự sinh tổng hợp cellulase từ chủng $B$. amyloliquefaciens D19 nhằm đáp ứng các nhu cầu ứng dụng thực tiễn của enzyme này.

\section{VẠT LIỆ VÀ PHƯỚnG PHÁP}

\subsection{Vật liệu}

Chủng vi khuẩn B. amyloliquefaciens D19 được phân lập từ đất ở Thành phố Hồ Chí Minh, đã được định danh ở mức phân tử bằng phương pháp giải trình tự đoạn gen $16 \mathrm{~S}$ rRNA bởi phòng thí nghiệm Công nghệ động vật (Trường Đại học Konkuk, Seoul, Hàn quốc) với cặp mồi được sử dụng là 27FAGAGTTTGATCCTGGCTCAG và 1492R 5'-GGTTACCTTGTTACGACTT-3' [9]. Kết quả định danh này đã từng được công bố bởi nghiên cứu trước đây [10]. Kết quả giải trình tự được so sánh với cơ sở dữ liệu 16S-rRNA của các vi khuẩn có sẵn trên National Center for Biotechnology Information (NCBI) để xác định đến mức độ loài. Chủng vi khuẩn được lưu lưu giữ tại Bộ môn Công nghệ Sinh học, Viện Công nghệ Sinh học và Thực phẩm, Trường Đại học Công nghiệp Tp. $\mathrm{HCM}$ ở điều kiện $-20^{\circ} \mathrm{C}$ và được hoạt hoá 12 giờ trong môi trường Luria-Bertani broth (LB broth) ở $37^{\circ} \mathrm{C}$ trước khi thực hiện các nghiên cứu tiếp theo.

\subsection{Phương pháp}

\subsubsection{Phương pháp xây dụng đường cong tăng trưởng của vi khuẩn}

Chủng vi khuẩn $B$. amyloliquefaciens $\mathrm{D} 19$ từ bộ sưu tập giống được hoạt hoá 12 giờ trong môi trường LB broth ở $37^{\circ} \mathrm{C}$, lắc 150 vòng/phút trong 16 giờ ở điều kiện $37^{\circ} \mathrm{C}$. Giống đã được hoạt hóa trong $5 \mathrm{ml}$ môi trường $\mathrm{LB}$, sau đó tiếp tục được cấy vào trong $50 \mathrm{ml}$ môi trường $\mathrm{LB}$ lỏng có bổ sung $1 \% \mathrm{CMC}$, lắc 150 vòng/phút trong 16 giờ ở $37^{\circ} \mathrm{C}$. Sau đó, $10 \mathrm{ml}$ giống tăng sinh được cấy vào $100 \mathrm{ml}$ môi trường LB lỏng có bổ sung $1 \% \mathrm{CMC}$, lắc 150 vòng/phút và giá trị $\mathrm{OD}_{600 \mathrm{~nm}}$ của dịch huyền phù được xác định sau mỗi 2 giờ, liên tục trong 24 giờ để khảo sát đường cong tăng trưởng. Đường cong tăng trưởng được phân tích và vẽ bởi phần mềm GraphPad Prism 8 [11].

\subsubsection{Phương pháp xác định khả năng sinh tổng hợp cellulase của vi khuẩn}

B. amyloliquefaciens $\mathrm{D} 19$ được cấy theo phương pháp cấy điểm trên đĩa thạch LB có bổ sung $0,5 \% \mathrm{CMC}$. Chủng này sẽ được nuôi ủ ở $37^{\circ} \mathrm{C}$ trong 72 giờ. Sau 72 giờ, lugol được trải đều trên bề mặt đĩa thạch và quan sát vòng phân giải. Khả năng sinh tổng hợp cellulase được đánh giá bằng độ lớn của vòng phân giải $\mathrm{A}=\mathrm{D}-\mathrm{d}$ với $\mathrm{D}$ là đường kính vòng phân giải $(\mathrm{mm})$ và $\mathrm{d}$ là đường kính khuẩn lạc $(\mathrm{mm})$. Độ lớn của vòng phân giải càng lớn phản ánh hoạt tính enzyme càng mạnh và ngược lại [12].

\subsubsection{Phương pháp khảo sát điều kiện sinh tổng hợp cellulase tù̀ B. amyloliquefaciens D19}

Ảnh hưởng của các loại chất cảm ứng lên khả năng sinh tổng hợp cellulase của chủng vi khuẩn $B$. amyloliquefaciens D19 được khảo sát trên 6 loại nguyên liệu có thành phần chính là cellulose như rơm, trấu, bã mía, mùn cưa, xơ dừa, $\mathrm{CMC}$. Môi trường nuôi cấy cơ bản được sử dụng là $\mathrm{LB}$ lỏng $(10 \mathrm{~g} / \mathrm{L}$ tryptone, $5 \mathrm{~g} / \mathrm{L}$ yeast extract, $10 \mathrm{~g} / \mathrm{L} \mathrm{NaCl}, 20 \mathrm{~g} / \mathrm{L}$ agar, $\mathrm{pH} 7,0)$ có bổ sung $1 \% \mathrm{CMC}(\mathrm{w} / \mathrm{v})$. Rơm, trấu, bã mía, xơ dừa, mùn cưa được sử dụng để thay thế $\mathrm{CMC}$ trong các nghiệm thức khác nhau. Mỗi chất cảm ứng được xay nhuyễn và bổ sung vào môi trường $\mathrm{LB}$ lỏng với tỉ lệ $1 \%(\mathrm{w} / \mathrm{v})$. Khuẩn lạc của chủng $\mathrm{D} 19$ được hoạt hóa, sau đó tăng sinh ở $37^{\circ} \mathrm{C}$ trong điều kiện nuôi cấy lắc ( 150 vòng/phút). Mật độ tế bào được xác định bằng phương pháp đo $\mathrm{OD}$ ở bước sóng $600 \mathrm{~nm}$ đạt giá trị khoảng 0,8 sẽ được cấy vào môi trường nuôi cấy với tỉ lệ $1 \%$. Quá trình lên men thu nhận enzyme được thực hiện ở điều kiện nhiệt độ $37^{\circ} \mathrm{C}, 150$ vòng/phút. Sau mồi 12 giờ nuôi cấy, dịch enzyme thô được thu nhận bằng cách ly tâm tách tế bào khỏi dịch nuôi cấy 
với vận tốc $13000 \mathrm{rpm}$ trong 10 phút ở $4^{\circ} \mathrm{C}$ và xác định hoạt tính. Loại chất cảm ứng cho hoạt tính cellulase của dịch enzyme thô cao nhất sẽ được chọn để để tiến hành các thử nghiệm tiếp theo.

Ảnh hưởng của nồng độ chất cảm ứng lên khả năng sinh tổng hợp cellulase của chủng D19 cũng được khảo sát trên chất cảm ứng thích hợp được chọn từ thí nghiệm trước với các giá trị nồng độ khác nhau $0 \% 0,5 \%$, $1 \%, 2 \%, 3 \%, 4 \%$ (w/v). Quá trình nuôi cấy và thu dịch enzyme thô được tiến hành tương tự như trên. Nồng độ chất cảm ứng cho hoạt tính cellulase của dịch enzyme thô cao nhất sẽ được chọn để thực hiện các thử nghiệm xác định nguồn nitrogen thích hợp tiếp theo.

Các nguồn nitrogen vô cơ lẫn hữu cơ như $\mathrm{NaNO}_{3},\left(\mathrm{NH}_{2}\right)_{2} \mathrm{CO}, \mathrm{NH}_{4} \mathrm{NO}_{3},\left(\mathrm{NH}_{4}\right)_{2} \mathrm{SO}_{4}, \mathrm{NH}_{4} \mathrm{Cl}$, peptone, bột đậu nành, bột trùn quế được bổ sung thay thế cho tryptone trong thí nghiệm khảo sát ảnh hưởng của các nguồn nitrogen lên sự sinh tổng hợp cellulase. Các muối $\mathrm{NaNO}_{3},\left(\mathrm{NH}_{2}\right)_{2} \mathrm{CO}, \mathrm{NH}_{4} \mathrm{NO}_{3},\left(\mathrm{NH}_{4}\right)_{2} \mathrm{SO}_{4}, \mathrm{NH}_{4} \mathrm{Cl}$ được quy đổi theo tỉ lệ $1 \%(\mathrm{w} / \mathrm{v})$ hàm lượng nguyên tố nitrogen có trong môi trường, còn peptone, bột đậu nành, bột trùn quế được bổ sung với lượng $1 \mathrm{~g} / 100 \mathrm{ml}$ môi trường. Chủng $\mathrm{D} 19$ được nuôi cấy và dịch enzyme thô được thu nhận như các thí nghiệm trên. Nguồn nitrogen cho hoạt tính cellulase của dịch enzyme thô cao nhất sẽ được chọn để xây dựng môi trường sinh tổng hợp cellulase của vi khuẩn.

Ngoài ra, chúng tôi còn khảo sát sự ảnh hưởng của các nguồn carbon khác nhau lên sự sinh tổng hợp cellulase của B. amyloliquefaciens D19 để chọn lọc nguồn carbon thích hợp. Môi trường nuồi cấy có chứa chất cảm ứng với nồng độ thích hợp và nguồn nitrogen được chọn từ kết quả thí nghiệm trước làm mẫu đối chứng, các nghiệm thức khác được bổ sung thêm $0,5 \%$ (w/v) nguồn carbon như D-Glucose, Sucrose, Arabinose, Maltodextrin. Việc nuôi cấy và thu nhận enzyme thô được tiến hành tương tự như các thí nghiệm trên.

Bên cạnh các thành phần môi trường như chất cảm ứng, nguồn nitrogen và nguồn carbon, các điều kiện nuôi cấy như $\mathrm{pH}$ ban đầu và nhiệt độ cũng có ảnh hưởng đến sự sinh tổng hợp cellulase của chủng D19. Do đó, thí nghiệm này được tiến hành với môi trường nuôi cấy được pha chế theo kết quả được chọn của thí nghiệm trước có điều chỉnh các giá trị pH ban đầu khác nhau 3,0-9,0. Nhiệt độ được khảo sát ở các giá trị $25^{\circ} \mathrm{C}, 30^{\circ} \mathrm{C}, 37^{\circ} \mathrm{C}, 40^{\circ} \mathrm{C}, 45^{\circ} \mathrm{C}$. Quá trình nuôi cấy và thu dịch enzyme thô được tiến hành như các thí nghiệm trước.

\subsubsection{Phưong pháp xác định hoạt tính cellulase}

Hoạt tính cellulase được xác định theo phương pháp Bernfeld. Phương pháp này dựa trên cơ sở khi cho đường khử (sản phẩm thủy phân của cellulose) phản ứng với thuốc thử 3,5-acid dinitrosalicylic (DNS) có màu vàng tạo thành 3-amino,5-nitro salicylic acid có màu đỏ cam và hấp thụ cực đại ở bước sóng $540 \mathrm{~nm}$. Cường độ màu của sản phẩm phản ứng tỷ lệ thuận với lượng đường khử được tạo ra nhờ hoạt động xúc tác của cellulase. Dịch nuôi cấy vi khuẩn sau khi đã được ly tâm loại bỏ tế bào được cho phản ứng với dung dịch $\mathrm{CMC} 1 \%$ trong 30 phút, sau đó thuốc thử DNS được thêm vào để xác định lượng đường khử được giải phóng. Đơn vị hoạt tính (UI) của cellulase được xác định là lượng enzyme cần thiết để xúc tác cho phản ứng phân giải cellulose tạo thành một micromole đường khử trong thời gian một phút [13].

\subsubsection{Phương pháp xử lý số liệu}

Giá trị kết quả của các thí nghiệm là trung bình của 3 lần lặp lại. Số liệu thô được tính toán và biểu đồ được vẽ bằng phần mềm Microsoft Excel 2010. Kết quả được xử lý thống kê bằng phần mềm Stagraphics XVI với hàm ANOVA, mức rủi ro $\alpha=0,05$.

\section{KẾT QUẢ VÀ THẢO LUẬN}

\section{1 Đặc điểm hình thái đại thể, vi thể và khả năng sinh tổng họ̣p cellulase của chủng $B$. amyloliquefaciens D19}

Nhằm khẳng định chủng vi khuẩn nghiên cứu là $B$. amyloliquefaciens và không bị tạp nhiễm, chủng D19 đã được kiểm tra các về hình thái khuẩn lạc, nhuộm Gram và nhuộm bào tử. Khuẩn lạc của chủng D19 trên môi trường $\mathrm{LB}$ ơ $37^{\circ} \mathrm{C}$ trong 48 giờ có kích thước $0,3-0,5 \mathrm{~cm}$, bề mặt khô, màu trắng đục, tròn, rìa không đều, có nhiều nếp nhăn gồ cao lõm ở tâm tạo thành các hình lỗ tròn (Hình $1 \mathrm{~A})$. Kết quả nhuộm Gram chứng minh chủng vi khuẩn hình que và thuộc nhóm Gram dương do còn giữ màu với tím tinh thể (Hình $1 \mathrm{~B})$. Khả năng hình thành nội bào tử của chủng vi khuẩn được xác nhận bằng phương pháp nhuộm với malachite green và safranin với nội bào tử bắt màu xanh và tế bào sinh dưỡng bắt màu đỏ (Hình $1 \mathrm{C}$ ). 

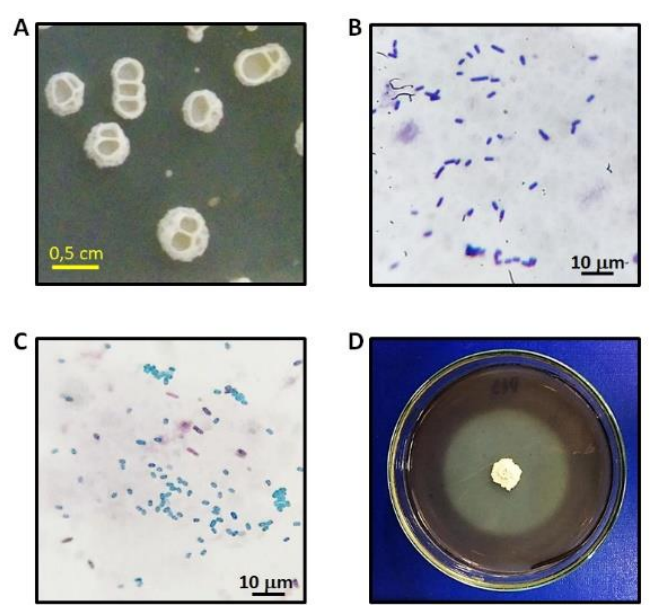

Hình 1: Hình thái khuẩn lạc của chủng B. amyloliquefaciens $\mathrm{D} 19$ sau 48 giờ nuôi ủ trên môi trường $\mathrm{LB}$ ở $37^{\circ} \mathrm{C}(\mathrm{A})$. Hình ảnh nhuộm Gram ở độ phóng đại X1000 (B). Hình ảnh nhuộm bào tử ở độ phóng đại X1000 (C). Khả năng phân giải cellulose của $\mathrm{D} 19$ sau 72 giờ nuôi ủ trên môi trường $\mathrm{LB}$ agar có bổ sung $0,5 \% \mathrm{CMC}(\mathrm{D})$.

Chủng B. amyloliquefaciens D19 được cấy chấm điểm trên môi trường $\mathrm{LB}$ agar có bổ sung $1 \% \mathrm{CMC}(\mathrm{w} / \mathrm{v})$ và ủ ở $37^{\circ} \mathrm{C}$ trong vòng 72 giờ và quan sát vòng phân giải nhờ thuốc thử Lugol. Sự phân hủy CMC trên đĩa thạch của chủng $B$. amyloliquefaciens D19 cho đường kính vòng phân giải có độ lớn là $3,1 \pm 0,2 \mathrm{~cm}$ (Hình $1 \mathrm{D})$. Kết quả này tương đối cao hơn so với chủng vi khuẩn Bacillus $\mathrm{sp}$. $(2,38 \mathrm{~cm})$ trong nghiên cứu của tác giả Mai Thi và cộng sự năm 2017 [14]. Điều này cho thấy chủng vi khuẩn B. amyloliquefaciens D19 có tiềm năng lớn trong việc thu nhận cellulase có hoạt tính cao.

\section{3 Đường cong tăng trưởng của chủng B. amyloliquefaciens D19}

Tốc độ phân chia tế bào và hoạt động trao đổi chất của vi sinh vật (VSV) ở mỗi giai đoạn tăng trưởng là khác nhau. Do đó, nhằm xác định tuổi giống thích hợp của chủng D19 dùng cho các thí nghiệm khảo sát thành phần và điều kiện nuôi cấy, chúng tôi đã khảo sát đường cong tăng trưởng của chủng vi khuẩn này trên môi trường $\mathrm{LB}$ lỏng có bổ sung $1 \% \mathrm{CMC}(\mathrm{w} / \mathrm{v})$, lắc 150 vòng/phút, ở $37^{\circ} \mathrm{C}$ trong vòng 24 giờ và xác định mật độ tế bào ở bước sóng $600 \mathrm{~nm}$ sau mỗi 2 giờ. Đường cong tăng trưởng được phân tích và vẽ bởi phần mềm GraphPad Prism 8 (Hình 2) với giá trị R ${ }^{2}=0,9933$.

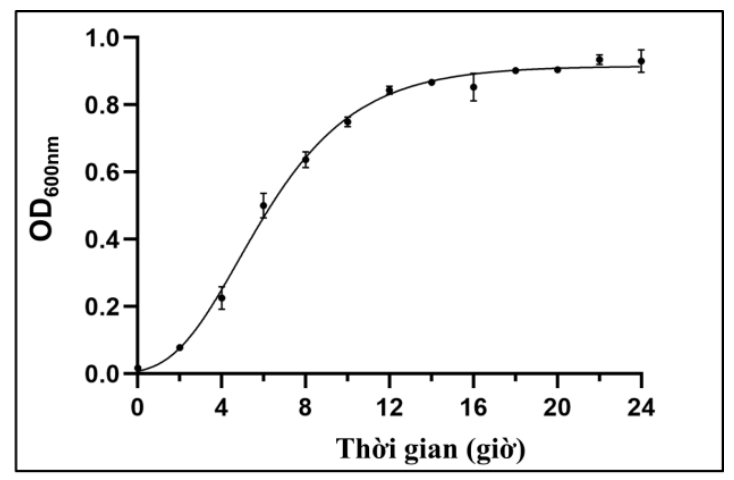

Hình 2: Đường cong tăng trưởng của $B$. amyloliquefaciens D19 trong môi trường $\mathrm{LB}+1 \% \mathrm{CMC}$

Kết quả cho thấy sau 12 giờ nuôi cấy, chủng vi khuẩn này bắt đầu vào pha cân bằng. Giai đoạn cuối pha tăng trưởng theo hàm mũ (pha $\log$ ) và đầu pha cân bằng là thời điểm mật độ vi sinh vật đạt cao nhất cùng với hoạt động trao đổi chất mạnh, do đó mốc thời gian 12 giờ sau khi tăng sinh được chọn để làm tuổi giống áp dụng cho các thí nghiệm về sau.

\section{4 Ảnh hưởng của các chất cảm ứng lên sự sinh tổng hợp cellulase của B. amyloliquefaciens D19}

Các enzyme ngoại bào được sinh tổng hợp mạnh mẽ trong điều kiện có hiện diện của cơ chất cảm ứng. Chính vì vậy, chất cảm ứng đóng vai trò quan trọng trong việc kích thích sự sinh tổng hợp của enzyme ngoại bào cellulase. Trong thí nghiệm này, $\mathrm{CMC}$, rơm, trấu, bã mía, xơ dừa, mùn cưa được sử dụng làm chất cảm ứng sinh tổng hợp cellulase từ chủng B. amyloliquefaciens D19, kết quả được thể hiện ở Hình 3. 

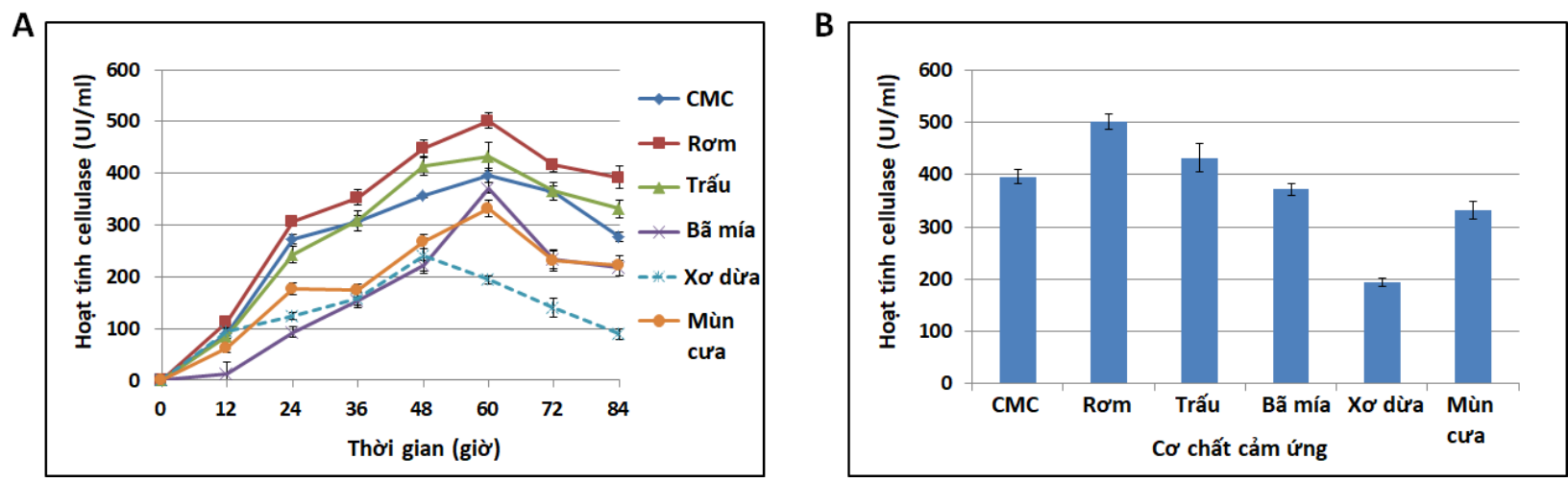

Hình 3. Hoạt tính cellulase của dịch nuôi cấy B. amyloliquefaciens D19 trong môi trường có bổ sung các chất cảm ứng khác nhau theo thời gian $(\mathrm{A})$ và ở thời điểm 60 giờ nuôi cấy $(\mathrm{B})$.

Kết quả cho thấy chủng $B$. amyloliquefaciens D19 có khả năng sinh tổng hợp cellulase dưới sự ảnh hưởng của cả 6 loại chất cảm ứng. Tuy nhiên, hoạt tính cellulase thu nhận được từ thí nghiệm với rơm đạt cao nhất ở tất cả các thời điểm (Hình $3 \mathrm{~A}$ ). Ngoại trừ môi trường có cơ chất cảm ứng là xơ dừa, 60 giờ là thời điểm dịch nuôi cấy có hoạt tính cellulase cao nhất với hoạt tính enzyme thu được là $501,34 \pm 14,38 \mathrm{UI} / \mathrm{ml}$, $431,66 \pm 27,08 \mathrm{UI} / \mathrm{ml}, 396,32 \pm 13,25 \mathrm{UI} / \mathrm{ml}, 371,84 \pm 10,46 \mathrm{UI} / \mathrm{ml}, 331,74 \pm 16,19 \mathrm{UI} / \mathrm{ml}, 194,42 \pm 7,79$ $\mathrm{UI} / \mathrm{ml}$ tương ứng với các chất cảm ứng rơm, trấu, $\mathrm{CMC}$, bã mía, mùn cưa và xơ dừa theo thứ tự từ cao đến thấp (Hình 3B).

Như vậy, khả năng cảm ứng sinh tổng hợp cellulase của xơ dừa và mùn cưa là thấp nhất. Trong nghiên cứu của Mangalanayaki và Aruna năm 2017, cellulase thu nhận được bởi chủng Bacillus subtilis phân lập tại Ấn Độ cũng cho hoạt tính rất thấp sau khi nuôi cấy trên môi trường có cơ chất là xơ dừa và mùn cưa [15]. Ngược lại khi được cảm ứng bằng rơm, cellulase thu nhận được cho hoạt tính cao hơn những chất còn lại và cao gấp 2,5 lần so với xơ dừa. Điều này có thể giải thích là do rơm có cấu trúc cellulose khá thưa và lỏng lẻo với thành phần chính là hemicellulose và khoảng $10 \%$ lignin trong khi mùn cưa và xơ dừa có cấu trúc cellulose khá dày và cứng với thành phần lignin chiếm đến 30-40\%. Kết quả này tương đương với nghiên cứu của Ashita Dhillon và cộng sự năm 2000 cho thấy rơm là nguyên liệu cảm ứng thích hợp nhất cho sự tổng hợp cellulase của chủng Bacillus circulans $\mathrm{AB}$ [16]. Ngoài ra, trên thế giới hiện nay cũng đã có một số nghiên cứu sử dụng rơm để thu nhận enzyme như nghiên cứu của Varsha Goyal và cộng sự năm 2014 đã nuôi cấy chủng Bacillus sp. 313SI trên môi trường có chứa rơm để thu nhận CMCase [17]. Rơm là một loại phế phụ phẩm nông nghiệp chiếm tỷ lệ cao, đặc biệt ở nước có nên nông nghiệp lúa nước lâu đời như Việt Nam. Chính vì vậy, với khả năng sinh tổng hợp cellulase có hoạt tính cao nhờ chất cảm ứng là rơm, B. amyloliquefaciens D19 này sẽ là một chủng vi khuẩn tiềm năng, góp phần quan trọng trong việc sản xuất cellulase thương mại với chi phí tiết kiệm. Thêm vào đó, rơm cũng là một trong những nguồn cơ chất rẻ và dồi dào cho nhiều ngành công nông nghiệp, trong đó ứng dụng cellulase để sản xuất nhiên liệu sinh học từ rơm đã và đang là mục tiêu quan trọng, góp phần cho sự phát triển bền vững của môi trường [18]. Từ những lý do trên, rơm được chọn là chất cảm ứng thích hợp cho việc sinh tổng hợp cellulase của $B$. amyloliquefaciens D19 để tiến hành các khảo sát tiếp theo.

\section{5 Ảnh hưởng của nồng độ chất cảm ứng lên sự sinh tổng hợp cellulase của chủng $B$. amyloliquefaciens D19}

Chất cảm ứng có nồng độ khác nhau cũng ảnh hưởng đến sự sinh tổng hợp cellulase của vi khuẩn. Trong thí nghiệm này, chúng tôi tiến hành thay đổi nồng độ rơm bổ sung vào môi trường nuôi cấy với các tỷ lệ $0 \%, 0,5 \%, 1 \%, 2 \%, 3 \%, 4 \%$ để xác định sự ảnh hưởng của nồng độ chất cảm ứng đến sự sinh tổng hợp cellulase của B. amyloliquefaciens D19 và kết quả được thể hiện ở Hình 4. 

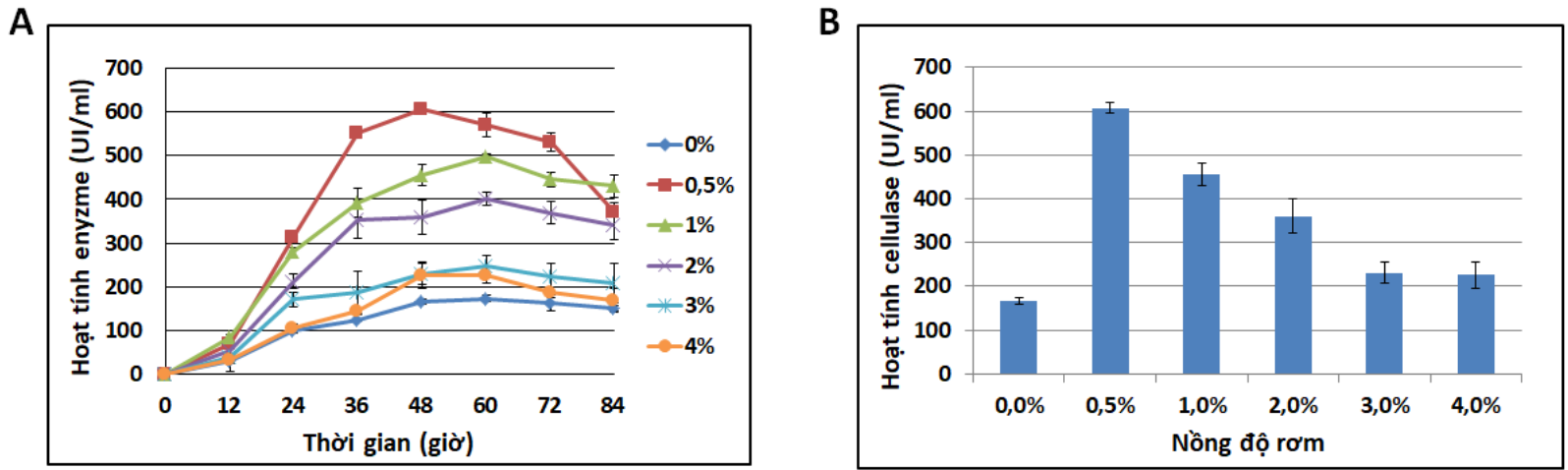

Hình 4: Hoạt tính cellulase của dịch nuôi cấy B. amyloliquefaciens D19 trong môi trường có bổ sung rơm với các nồng độ khác nhau theo thời gian $(\mathrm{A})$ và ở thời điểm 48 giờ nuôi cấy $(\mathrm{B})$.

Kết quả cho thấy hoạt tính cellulase ở các nồng độ khác nhau có sự khác biệt rõ ràng. Tuy nhiên, hoạt tính cellulase không tuyến tính theo sự tăng nồng độ chất cảm ứng (Hình $4 \mathrm{~A}$ ). Enzyme này cho hoạt tính cao nhất là $607,39 \pm 12,99 \mathrm{UI} / \mathrm{ml}$ sau 48 giờ nuôi cấy khi bổ sung $0,5 \%$ chất cảm ứng vào môi trường nuôi cấy. Hoạt tính này giảm dần khi tăng nồng độ chất cảm ứng lên $1 \%, 2 \%, 3 \%$ và $4 \%$. Kết quả này có thể do mật độ rơm trong môi trường càng nhiều sẽ làm thu hẹp môi trường sống của vi sinh vật, ngoài ra do có tỷ trọng thấp, rơm còn ảnh hưởng đến sự đảo trộn của môi trường và độ thông khí trong mồi trường, từ đó làm giảm khả năng trao đổi chất và sinh trưởng của vi sinh vật. Tương tự trong nghiên cứu của Yogita Lugani và cộng sự năm 2015 cũng cho thấy khi tăng nồng độ chất cảm ứng CMC lên 1,5\%,2\% và 2,5\% thì hoạt tính enzyme thu được từ chủng Bacillus sp. Y3 bị giảm rõ rệt [19]. Đồng thời, kết quả nghiên cứu của chúng tôi tương đương với nồng độ $0,75 \%$ rơm mà Goyal và cộng sự năm 2014 đã sử dụng để thu nhận CMCase [17]. Bên cạnh đó, kết quả phân tích thống kê cho thấy sự khác biệt đáng kể giữa hàm lượng rơm $0,5 \%$ so với các nồng độ khác $(\mathrm{p}<0,05)$. Chính vì vậy, chúng tôi chọn tỉ lệ rơm $0,5 \%$ để tiến hành các khảo sát tiếp theo.

\section{6 Ảnh hưởng của các nguồn nitrogen lên sự sinh tổng hợp cellulase của chủng B. amyloliquefaciens D19}

Nguồn nitrogen đóng vai trò thiết yếu trong quá trình chuyển hóa và trao đổi chất của vi sinh vật. Do đó, thí nghiệm này được tiến hành nhằm khảo sát sự ảnh hưởng của các nguồn nitrogen khác nhau đến sự sinh tổng hợp cellulase của chủng $\mathrm{D} 19$ bằng cách sử dụng môi trường nuôi cấy có bổ sung $0,5 \%$ rơm và các nguồn nitrogen vô cơ cũng như hữu cơ như: $\mathrm{NaNO}_{3},\left(\mathrm{NH}_{2}\right)_{2} \mathrm{CO}, \mathrm{NH}_{4} \mathrm{NO}_{3},\left(\mathrm{NH}_{4}\right)_{2} \mathrm{SO}_{4}, \mathrm{NH}_{4} \mathrm{Cl}$, peptone, bột đậu nành và bột trùn quế. Hoạt tính cellulase thu nhận sau mỗi 12 giờ nuôi cấy được thể hiện ở Hình $5 \mathrm{~A}$.
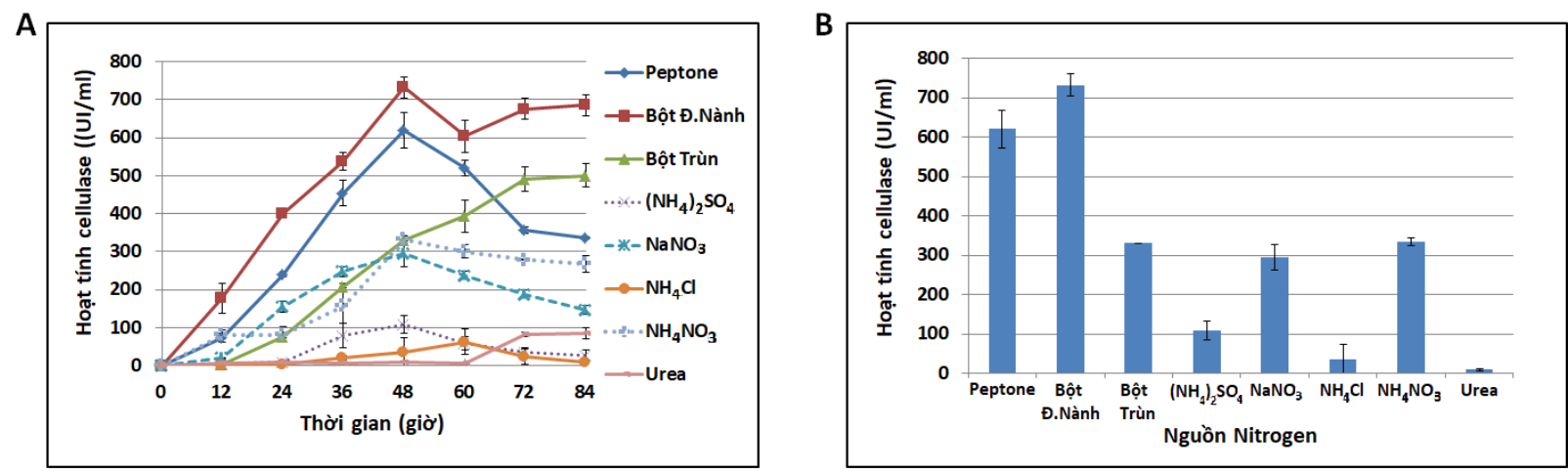

Hình 5: Hoạt tính cellulase của dịch nuôi cấy B. amyloliquefaciens D19 trong môi trường có bổ sung các nguồn nitrogen khác nhau theo thời gian $(\mathrm{A})$ và ở thời điểm 48 giờ nuôi cấy $(\mathrm{B})$.

Kết quả cho thấy chủng D19 hầu như không sinh tổng hợp cellulase trong môi trường có chứa Urea, $\left(\mathrm{NH}_{4}\right)_{2} \mathrm{SO}_{4}, \mathrm{NH}_{4} \mathrm{Cl}$. Đối với hai loại muối $\mathrm{NaNO}_{3}$ và $\mathrm{NH}_{4} \mathrm{NO}_{3}$, chủng $\mathrm{D} 19$ này đã sử dụng $\mathrm{NO}_{3}^{-}$làm nguồn nitrogen cho quá trình sinh trưởng và trao đổi chất của chúng và hoạt tính cellulase thu nhận được cao hơn các nguồn nitrogen vô cơ còn lại. Điều này cũng thể hiện trong kết quả nghiên cứu của Yogita và cộng sự năm 2015 [19]. Tuy nhiên, $\mathrm{NO}_{3}^{-}$vẫn không phải là nguồn nitrogen thích hợp nhất đối với chủng vi khuẩn này nên hoạt tính cellulase thu được chưa đạt cao nhất. Đối với các nguồn nitrogen hữu cơ như peptone, bột đậu nành, bột trùn quế, có thể thấy hoạt tính cellulase thu nhận được cao hơn so với các nguồn nitrogen 
còn lại. Đối với nguồn nitrogen là bột trùn quế, mặc dù có hàm lượng protein tương đối cao nhưng cellulase thu nhận được đến thời điểm 60 giờ trở đi thì hoạt tính mới có sự tăng lên rõ rệt. Điều này cho thấy chủng vi khuẩn D19 cần có thời gian dài để phân hủy các protein trong trùn quế để sử dụng nguồn đạm có trong trùn quế và dẫn đến quá trinh sinh tổng hợp cellulose cũng chậm hơn. Bên cạnh đó, peptone là hỗn hợp các peptide và amino acid được tạo ra bởi quá trình thủy phân protein, do vậy, vi khuẩn dễ dàng sử dụng để phát triển và trao đổi chất nhưng hoạt tính thu nhận được chưa cao bằng môi trường có chứa bột đậu nành. Không chỉ chứa thành phần chủ yếu là protein, bột đậu nành còn có các thành phần dinh dưỡng khác như lipid, nhiều loại amino acid cần thiết như lysine, tryptophan, valine, methionine,... cùng nhiều loại khoáng chất và vitamin [20]. Khi bổ sung bột đậu nành vào môi trường nuôi cấy, ngoài việc cung cấp các chất dinh dưỡng cơ bản còn đáp ứng được nhu cầu về các yếu tố tăng trưởng của vi khuẩn. Ngoài ra, bột đậu nành còn có chứa một lượng nhỏ cellulose, cũng là nguồn chất cảm ứng sinh cellulase nên có thể đây cũng là nguyên nhân mà hoạt tính enzyme cellulose thu được khi nuôi cấy trong môi trường này đạt cao nhất. Cho đến nay, đã có nhiều nghiên cứu chứng minh bột đậu nành đóng vai trò quan trọng trong việc sản xuất cellulase từ vi sinh vật như nghiên cứu của Saravanan và cộng sự năm 2012 đã bổ sung bột đậu nành với lượng $22,5 \mathrm{~g} / 1$ vào môi trường nuôi cấy Trichoderma reesei, cho hoạt tính cellulase cao hơn so với khi bổ sung các nguồn nitrogen khác [21]. Ngoài ra, Miao Ye và cộng sự (2017) đã bổ sung bột đậu nành (3\%) vào môi trường lên men để thu nhận cellulase từ chủng $B$. amyloliquefaciens $\mathrm{S} 1$ [6]. Trong nghiên cứu của chúng tôi, ở thời điểm 48 giờ, hoạt tính cellulase thu nhận được trong môi trường có bổ sung bột đậu nành

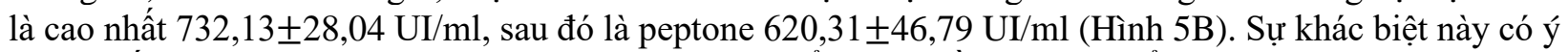
nghĩa thống kê $(\mathrm{p}<0,05)$ nên bột đậu nành được chọn để làm nguồn nitrogen bổ sung vào môi trường trong các khảo sát tiếp theo.

\section{7 Ảnh hưởng của các nguồn carbon lên sự sinh tổng hợp cellulase của chủng B. amyloliquefaciens D19}

Thí nghiệm này được tiến hành nhằm khảo sát khả năng sinh tổng hợp cellulase của chủng $\mathrm{D} 19$ với các nguồn carbon khác nhau trong môi trường lên men có bổ sung $0,5 \%$ rơm, $1 \%$ bột đậu nành và các nguồn carbon: D-Glucose, Sucrose, Arabinose, Maltodextrin với tỉ lệ $0,5 \%(\mathrm{w} / \mathrm{v})$, mẫu đối chứng là môi trường không bổ sung thêm bất kỳ nguồn carbon nào. Hoạt tính cellulase thu nhận sau mỗi 12 giờ nuôi cấy được thể hiện ở Hình $6 \mathrm{~A}$.
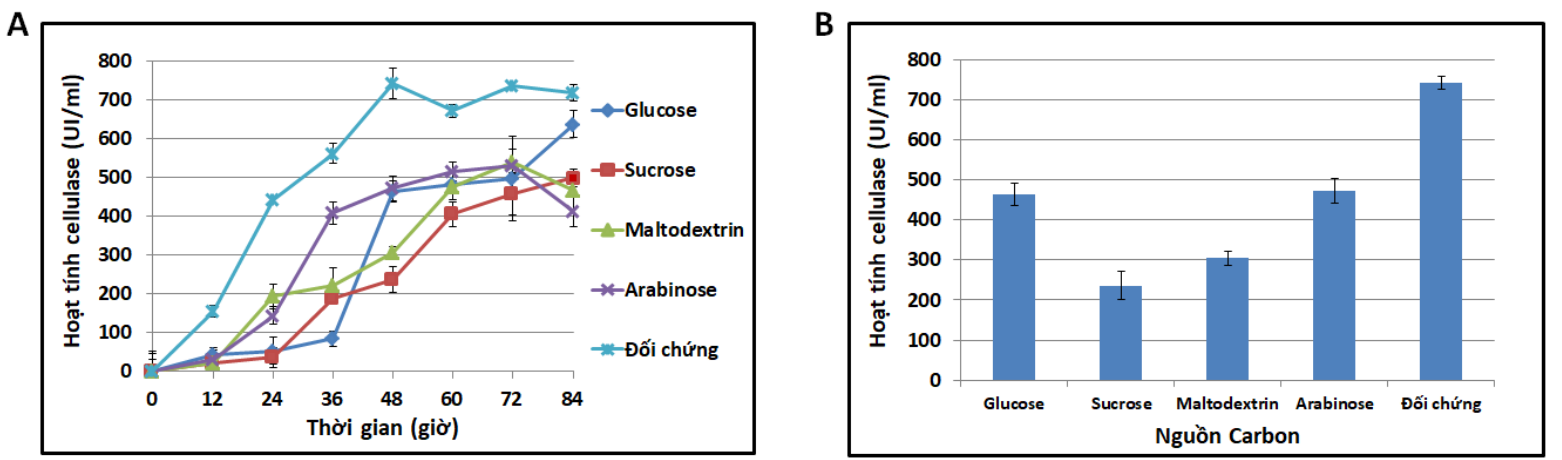

Hình 6: Hoạt tính cellulase của dịch nuôi cấy B. amyloliquefaciens D19 trong môi trường có bổ sung các nguồn carbon khác nhau theo thời gian $(\mathrm{A})$ và ở thời điểm 48 giờ nuôi cấy $(\mathrm{B})$.

Kết quả cho thấy trong môi trường không bồ sung thêm nguồn carbon thì hoạt tính cellulase thu được cao nhất ở tất cả các thời điểm cho thấy môi trường LB lỏng với nồng độ chất cảm ứng và nguồn nitrogen thích hợp sẽ kích thích quá trình sinh tổng hợp cellulase của vi khuẩn. Việc bổ sung thêm nguồn carbon ở các dạng đường khác nhau có thể làm gia tăng sự sinh trưởng của vi sinh vật nhưng không đồng nghĩa với sự gia tăng tổng hợp enzyme ngoại bào (Hình 6A). Tương tự như thí nghiệm trước, hoạt tính cellulase thu nhận được cao nhất ở thời điểm 48 giờ, đạt $741,82 \pm 40,29 \mathrm{UI} / \mathrm{ml}$ cao hơn đáng kể so với các môi trường khác, có ý nghĩa thống kê với p $<0,05$ (Hình $6 \mathrm{~B}$ ). Đối với các môi trường có bổ sung các nguồn carbon, có thể thấy hoạt tính cellulase không cao và không có sự khác biệt rõ ràng. Kết quả này có thể phần nào được giải thích dựa theo cơ chế ức chể dị hóa (catabolite repression). Theo đó, sự hiện diện của các loại đường đơn giản trong môi trường nuôi cấy sẽ ức chế hoạt động của một số yếu tố phiên mã đóng vai trò hoạt hóa sự biểu hiện các gene mã hóa cho cellulase và hemicellilase. Nghiên cứu của Vinay K. Singh và cộng sự năm 1998 cũng cho thấy khi bổ sung glucose và sucrose vào môi trường nuôi cấy thì hoạt tính cellulase của 
Bacillus brevis VS-1 bị giảm [22]. Điều này cũng được thể hiện trong nghiên cứu của Bobbie J. Stewart và cộng sự năm 1976 khi nuôi ủ Cellulomonas sp. trên đĩa thạch có chất cảm ứng và glucose, kết quả cho thấy không có vòng phân giải cellulose xung quanh khuẩn lạc [23]. Vì vậy, chúng tôi nhận định môi trường nuôi cấy không bổ sung thêm nguồn carbon là thích hợp cho sự sinh tổng hợp cellulase của chủng D19.

\section{8 Ảnh hưởng của pH ban đầu và nhiệt độ nuôi cấy lên sự sinh tổng hợp cellulase của chủng $B$. amyloliquefaciens D19}

Bên cạnh nguồn chất cảm ứng, nguồn nitrogen và carbon thì $\mathrm{pH}$ ban đầu và nhiệt độ nuôi cấy cũng là những yếu tố quan trọng ảnh hưởng đến sự sinh tổng hợp cellulase của vi khuẩn. Để xác định $\mathrm{pH}$ ban đầu thích hợp cho việc thu nhận cellulase có hoạt tính cao, môi trường nuôi cấy được điều chỉnh về các giá trị: 3,0 9,0 và nhiệt độ nuôi cấy được khảo sát ở $25^{\circ} \mathrm{C}-45^{\circ} \mathrm{C}$. Hoạt tính cellulase của dịch nuôi cấy sau mỗi 12 giờ được kiểm tra và thể hiện ở hình 7.
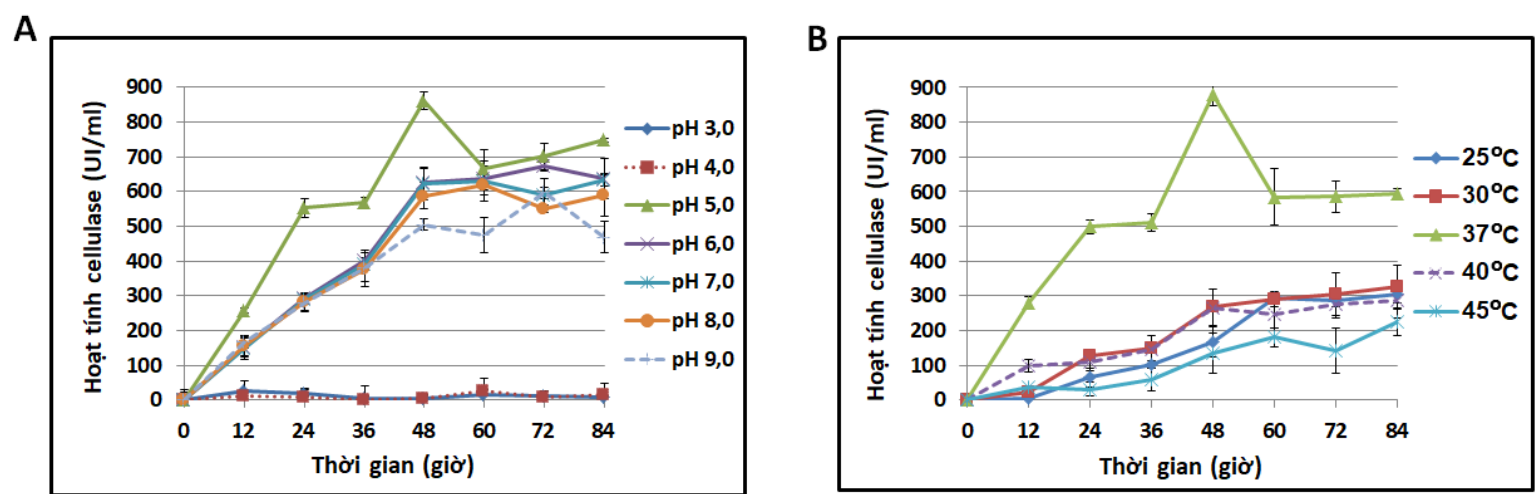

Hình 7. Hoạt tính cellulase của dịch nuôi cấy B. amyloliquefaciens D19 trong môi trường có các giá trị pH ban đầu khác nhau $(\mathrm{A})$ và ở các điều kiện nhiệt độ khác nhau $(\mathrm{B})$.

Kết quả cho thấy, chủng vi khuẩn D19 này hầu như không thể sinh tổng hợp cellulase có hoạt tính trong môi trường có $\mathrm{pH}$ ban đầu là 3,0 và 4,0 (Hình $7 \mathrm{~A}$ ). Tuy nhiên, khi tăng $\mathrm{pH}$ lên 5,0 thì hoạt tính cellulase thu được ở tất cả các thời điểm đều cao nhất và đặc biệt là ở 48 giờ, hoạt tính đạt $862,48 \pm 24,50 \mathrm{UI} / \mathrm{ml}$. Khi $\mathrm{pH}$ môi trường tăng lên 6,0 và 7,0 thì hoạt tính cellulase bị giảm gần $30 \%$ với các giá trị lần lượt là $627,95 \pm 42,76 \mathrm{UI} / \mathrm{ml}$ và $622,43 \pm 45,34 \mathrm{UI} / \mathrm{ml}$. Ở môi trường có $\mathrm{pH}$ ban đầu là 8,0 và 9,0 thì hoạt tính cellulase bị giảm rõ rệt hơn khi ghi nhận kết quả ở thời điểm 48 giờ lần lượt là $588,02 \pm 37,75 \mathrm{UI} / \mathrm{ml}$ và $505,17 \pm 15,97 \mathrm{UI} / \mathrm{ml}$. Mỗi loài vi khuẩn khác nhau thì sẽ có một giá trị $\mathrm{pH}$ ban đầu thích hợp để sinh trưởng và trao đổi chất. Trong một số nghiên cứu, ngưỡng $\mathrm{pH}$ tối ưu thường là $\mathrm{pH}$ trung tính như kết quả của Magdi và cộng sự (2010), chủng $B$. subtilis $\mathrm{KO}$ phân lập từ đất cho hoạt tính cellulase cao ở $\mathrm{pH}$ 6,5-7,0 [24]. Abou-Taleb và cộng sự (2009) cũng chỉ ra rằng chủng Bacillus alcalophilus S39 và $B$. amyloliquefaciens $\mathrm{C} 2$ sinh tổng hợp cellulase có hoạt tính đạt tối đa ở $\mathrm{pH}$ ban đầu là 7,0 [25]. Mặt khác, $\mathrm{pH} 3,5$ lại là $\mathrm{pH}$ thích hợp cho chủng Bacillus sp. sinh tổng hợp cellulase có hoạt tính cao và đạt tối sau 24 giờ lên men trong nghiên cứu của Maidul Islam và cộng sự [26]. Đối với chủng $B$. amyloliquefaciens D19 này, ngưỡng $\mathrm{pH}$ ban đầu thích hợp nhất là $\mathrm{pH} 5,0$ và kết quả này có sự khác biệt mang ý nghĩa thống kê $(\mathrm{p}<0,05)$. Chính vì vậy, $\mathrm{pH} 5,0$ được chọn là giá trị $\mathrm{pH}$ môi trường ban đầu thích hợp cho sự sinh tổng hợp cellulase của B. amyloliquefaciens D19.

Ngoài $\mathrm{pH}$ môi trường ban đầu, nhiệt độ nuôi cấy thích hợp nhất để chủng B. amyloliquefaciens D19 sinh tổng hợp cellulase là $37^{\circ} \mathrm{C}$ cũng đã được ghi nhận trong nghiên cứu này (Hình 7B). Tại nhiệt độ này sau 48 giờ nuôi cấy, hoạt tính cellulase thu nhận được là cao nhất, đạt $879,47 \pm 33,43 \mathrm{UI} / \mathrm{ml}$. Tương tự như $\mathrm{pH}$, mỗi loài VSV có một ngưỡng nhiệt độ thích hợp để sinh trưởng và thực hiện các quá trình trao đổi chất. Đa số các chủng B. amyloliquefaciens hoạt động tốt ở ngưỡng nhiệt độ $30^{\circ} \mathrm{C}-40^{\circ} \mathrm{C}$ [27]. Dễ dàng nhận thấy đối với chủng $\mathrm{D} 19$ này, ngưỡng nhiệt độ tối ưu để sinh tổng hợp cellulase là $37^{\circ} \mathrm{C}$. Kết quả này tương tự với nghiên cứu của You-Jung Lee và cộng sự cho thấy $37^{\circ} \mathrm{C}$ là nhiệt độ phù hợp nhất khi nuôi cấy chủng $E$. coli JM109/ DL-3 để sản xuất CMCase [28]. Nhiệt độ cao hơn hoặc thấp hơn $37^{\circ} \mathrm{C}$ có thể gây ảnh hưởng đến quá trình sinh tổng hợp cellulase cũng như phần nào ảnh hưởng đến hoạt tính của enzyme này. Điều này đã được thể hiện trong nghiên cứu tối ưu hóa các điều kiện lên men để thu nhận cellulase từ Bacillus sp. của Maidul Islam và công sự (2019), cellulase đạt hoạt tính cao nhất ở $35^{\circ} \mathrm{C}$ và khi nhiệt độ tăng đến $40^{\circ} \mathrm{C}$ thì hoạt tính enzyme bị giảm mạnh [26]. 


\section{KẾT LUẦN}

Nhằm góp phần khai thác hệ cellulase ngoại bào từ vi sinh vật để đáo ứng các nhu cầu thực tiễn hiện nay, đề tài nghiên cứu này đã được tiến hành nhằm xác định các điều kiện sinh tổng hợp cellulase của chủng vi khuẩn B. amyloliquefaciens D19, bao gồm nguồn cơ chất cảm ứng, nguồn nitrogen, nguồn carbon, $\mathrm{pH}$ ban đầu của môi trường, nhiệt độ nuôi cấy. Kết quả cho thấy hoạt tính cellulase thu nhận được có hoạt tính cao nhất là $879,47 \mathrm{UI} / \mathrm{ml}$ sau 48 giờ nuôi cấy chủng vi khuẩn $B$. amyloliquefaciens $\mathrm{D} 19$ trong môi trường có thành phần $0,5 \%$ rơm, $1 \%$ bột đậu nành, $0,5 \%$ cao nấm men, $1 \% \mathrm{NaCl}(\mathrm{w} / \mathrm{v})$. Ngoài thành phần môi trường, các điều kiện nuối cấy thích hợp cũng được xác định với nhiệt độ nuôi cấy là $37^{\circ} \mathrm{C} p H$ ban đầu là 5,0 và ở tốc độ lắc 150 vòng/phút.

\section{LỜI CẢM ƠN:}

Nghiên cứu này được thực hiện tại phòng thí nghiệm Công nghệ Vi sinh, Viện Công nghệ Sinh học và Thực phẩm, Trường Đại học Công nghiệp TP. HCM. Chúng tôi xin chân thành cảm ơn Ban Giám hiệu Trường Đại học Công nghiệp TP. HCM, Quý Thầy Cô của Viện Công nghệ Sinh học và Thực phẩm đã tạo điều kiện thuận lợi cho chúng tôi thực hiện nghiên cứu này.

\section{TÀI LIÊUU THAM KHẢO}

1. Mohammed, A.M., Aliyu S, Abubakar G., Aloy C. Ene, and J. A. Wafar, Studies on the use of agricultural wastes for cellulase enzyme production by Aspergillus niger. Research Journal of Agriculture and Biological Science, 2005. 1 (4):p. 325-328.

2. Shafaq A, M.M., Ikram N, Ghori MIs, Butt KY, Ahmed S, Kinetic study of carboxymethylcellulase from Trichoderma reesei. Pakistan Journal of Life and Social Sciences, 2004. 2(1):p. 1-4

3. Katzen, R. and D.J. Schell, Lignocellulosic Feedstock Biorefinery: History and Plant Development for Biomass Hydrolysis. Wiley online library. 2005: p. 129-138.

4. Sulzenbacher G, S.F., Morosoli R, Dupont C, Davies GJ, The Streptomyces lividans family 12 endoglucanase: construction of the catalytic core, expression, and X-ray structure at $1.75 \AA$ A resolution. Biochemistry, 1997.

5. Barkalow, D.G., Whistler, Roy L, Cellulose. AccessScience, McGraw-Hill, 2019.

6. Miao Ye, Linghong Sun, Ru Yang, Zaigui Wang, and KeZong Qi, The optimization of fermentation conditions for producing cellulase of Bacillus amyloliquefaciens and its application to goose feed. Royal Society Open Science, 2017. 4(10): p. 171012.

7. Irfan, M, Tayyab A, Hasan F, Khan S, Badshah M, and Shah A.A., Production and Characterization of Organic Solvent-Tolerant Cellulase from Bacillus amyloliquefaciens AK9 Isolated from Hot Spring. Applied Biochemistry and Biotechnology, 2017. 182(4): p. 1390-1402.

8. Jiangyan Cao, Ying Liu, Junjie Wang, Panpan Guo, and Zaigui Wang, Gene Cloning and Expression of Cellulase of Bacillus amyloliquefaciens Isolated from the Cecum of Goose. Animal Biotechnology, 2017. 28(1): p. $74-82$.

9. Medlin L, E.H., Stickel S, Sogin ML, The characterization of enzymatically amplified eukaryotic 16S-like rRNAcoding regions. Genes, 1988. 71: p. 491-499.

10. Nguyen Ngoc An, Hua Huynh Minh Thao, Ho Nguyen Hoang Yen, Nguyen Thi Dieu Hanh, Nguyen Thanh Hai, Bui Thi Luyen, Pham Tan Viet, Isolation, identification and characterization of bacterial antagonists of the dragon fruit fungal pathogen Neoscytalidium dimidiatum. Journal of Science and Technology - Industrial University of HCMC, 2020. In Press (Accepted Manuscript).

11. Kuhad R.C., Gupta R, Khasa Y.P., Bioethanol production from lignocellulosic biomass: an overview. Wealth from Waste, Teri Press, 2010. p. 53-106

12. Leboffe, M.J., Microbiology Laboratory Theory \& Application 2010: the United States of America. 2010.

13. Bernfeld, A.P., Methods in Enzymology. Methods in Enzymology, 1995. 1: p. 149-158.

14. Mai Thi, Nguyễn Hữu Hiệp và Dương Ngọc Thúy, Phân lập, nhận diện vi khuẩn phâhủy cellulose tù sùng (Holotrichia parallela) và trùn đất (Lubricus terrestris). Tạp chí Khoa học Trường Đại học Cần Thơ, 2017. 50: p. 81-90.

15. Mangalanayaki R., Aruna A., Production and optimization of cellulase by bacillus subtilis using coir waste and sawdust under solid state fermentation. World Journal of Pharmaceutical and medical research, 2018. 4: p. 102108.

16. Ashita Dhillon, J.K.G., B.M. Jauhari, S. Khanna, A cellulase-poor, thermostable, alkalitolerant xylanase produced by Bacillus circulans $A B 16$ grown on rice straw and its application in biobleaching of eucalyptus pulp. Bioresource Technology 2000. 73: p. 273-277.

17. Varsha Goyal, A.M., Anish Kumari Bhuwal, Gulab Singh, AnitaYadav and Neeraj Kumar Aggarwal Parametric Optimization of Cultural Conditions for Carboxymethyl Cellulase Production Using Pretreated Rice Straw by Bacillus sp. 313SI under Stationary and Shaking Conditions. Biotechnology Research International 2013. 2014. 
18. Passoth, V. and M. Sandgren, Biofuel production from straw hydrolysates: current achievements and perspectives. Appl Microbiol Biotechnol, 2019. 103(13): p. 5105-5116.

19. Yogita Lugani, R.S. and a.B.S. Sooch, Optimization of Cellulase Production from Newly Isolated Bacillus sp. Y3. J Bioprocess Biotech, 2015. 5(11).

20. Gorissen, Stefan H. M.; Crombag, Julie J. R.; Senden, Joan M. G.; Waterval, W. A. Huub; Bierau, Jörgen; Verdijk, Lex B.; van Loon, Luc J. C., Protein content and amino acid composition of commercially available plant-based protein isolates. Amino Acids, 2018. 50(12): p. 1685-1695.

21. Saravanan P., Muthuvelayudham R., and Viruthagiri T., Enhanced production of cellulase from pineapple waste by from respond surface methodology. Journal of Engineering, 2012. 2013.

22. Singh, V.K. and A. Kumar, Production and purification of an extracellular cellulase from Bacillus brevis VS-1. Biochem Mol Biol Int, 1998. 45(3): p. 443-52.

23. Stewart, B.J. and J.M. Leatherwood, Derepressed synthesis of cellulase by Cellulomonas. J Bacteriol, 1976. 128(2): p. 609-15.

24. Mandels, M. and E.T. Reese, Induction of cellulase in fungi by cellobiose. J Bacteriol, 1960. 79: p. 816-26.

25. Abou-Taleb, K.A.A., Mashhoor, W.A., Nasr, Sohair A., Sharaf, M.S. and and H.H.M. Abdel-Azeem, Nutritional and environmental factors affecting cellulase production by two strains of cellulolytic bacilli. Australian Journal of Basic and Applied Sciences, 2009. 3: p. 2429-2436.

26. Maidul Islam, Palash Kumar Shakar, A.K.M. Mohiuddin, and Md. Suzauddula, Optimization of fermentation condition for cellulase enzyme production fromBacillus sp. Malaysian Journal of Halal Research Journal (MJHR), 2019. 2(2).

27. F. G. Priest, M.G., L. A. Shute, R. C. W. Berkeley Bacillus amyloliquefaciens sp. nov., nom. rev. . International Journal of Systematic Bacteriology, 1987. 37: p. 69-71.

28. Lee, Y.J., et al., Purification and characterization of cellulase produced by Bacillus amyoliquefaciens DL-3 utilizing rice hull. Bioresour Technol, 2008. 99(2): p. 378-86.

Ngày nhận bài: 17/06/2020

Ngày chấp nhận đăng:23/09/2020 